Chapter 13

\title{
Energy-Dependent Mechanisms of Cholinergic Neurodegeneration
}

\author{
Agnieszka Jankowska-Kulawy, Anna Ronowska and \\ Andrzej Szutowicz \\ Additional information is available at the end of the chapter \\ http://dx.doi.org/10.5772/58339
}

\section{Introduction}

Dementia is a typical symptom of many neurodegenerative diseases. The characteristic feature of this pathology is preferential loss of cholinergic neurons in the brain septum, that are responsible for almost all cognitive functions in humans and animals. Alzheimer disease (AD) is one of the most common neurodegenerative diseases in elderly populations. There are estimations that 30 million people worldwide are suffering from $\mathrm{AD}$. Incidency of $\mathrm{AD}$ continues to grow, becoming not only a medical but also a socio-economical problem, especially when number of patients by 2050 will triple in connection with the lengthening of the human life span. The human brain constitutes only $2 \%$ of body weight, but consumes about $20 \%$ of the total body energy output under resting conditions. In contrast to other tissues, glucose is an almost exclusive energy substrate for the brain. In hypoxia or ketonemia brain may consume certain amounts of lactate and beta-hydroxybutyrate, which, however, cannot fully replace glucose to meet brain demands for energy. That is due to the fact that neurons, constituting $10 \%$ of all brain cells, produce and consume about $80 \%$ of its energy. In addition they have no capacity to store an inventory of high energy compounds. Therefore, the effective functioning of neurons is dependent on the continuous supply of equivalent amounts of glucose and oxygen. Most of the energy produced in the neurons, $(60-70 \%)$ is consumed for the maintenance and restoration of the pre-and postsynaptic membrane potentials.

Energy homeostasis of the brain is a very complex process due to the high sensitivity of neurons to metabolic stress, isolation of the brain due to the existence of the blood brain barrier, high energy requirements of the brain, and finally due to limited glycogen stores, as a dynamic source of energy. However the first step in neurodegeneration is mitochondrial dysfunction. This appears during some pathologic conditions such as: hypoxia, hypogly- 
cemia, amyloid $\beta$ accumulation, $\mathrm{Zn}, \mathrm{Fe}, \mathrm{Al}$ excess, free radicals formation and thiamine deficiency. All these pathologic signals strongly inhibited activity of the key enzymes engaged in energy metabolism.

In some cholinergic encephalopathies an impairment of brain energy metabolism occurs, a process known as hypometabolism. Studies of brain PET using $\left[{ }^{18} \mathrm{~F}\right]$ fluorodeoxyglucose reveal impaired glucose uptake and metabolism in different regions of an encephalopathic brain. The extent of these deficits correlates with the degree of cognitive impairment in the AD patients. On the other hand, PET combined with Pittsburgh compound-B application, can specifically determine the amyloid- $\beta$ accumulation in the patient's brain. Hence, it is possible to diagnose the AD in the early stages. Another characteristic feature of neurodegeneration of AD type, is inhibition of tricarboxylic acid cycle and the respiratory chain enzymes activities. Thus, there is a reduction in the synthesis and utilization of acetyl-CoA resulting from significant decreases in pyruvate dehydrogenase (PDHC) and $\alpha$-ketoglutarate dehydrogenase (KDHC) complex activities. Marked inhibition of aconitase and isocitrate dehydrogenase (IDH) activities was also reported in brain regions affected by AD pathology. This particular susceptibility of cholinergic neurons to several neurotoxic signals may be caused by the fact that they use acetylCoA not only to produce energy but also to synthesize acetylcholine. Thus the changes observed in $\mathrm{AD}$ brains concern he loss of several cholinergic markers including choline acetyltransferase (ChAT), acetylcholine esterase (AChE), high affinity choline uptake system (HACU), vesicular acetylcholine transporter (VAChT) and resulting from them reductions in ACh content and its quantal release. As a consequence, an impairment of signal transduction processes caused by a loss of muscarinic $\left(\mathrm{M}_{\mathrm{AChR}}\right)$ and nicotinic $\left(\mathrm{N}_{\mathrm{AChR}}\right)$ receptors and a decrease in the acetylcholine level take effect. The decrease of different cholinergic markers and protein levels were also observed post mortem in affected areas of human brain. It gives rise to a suggestion that impairment of cholinergic neurons in AD may precede later stages of the neurodegeneration process. These observations support the idea the key role of cholinergic dysfunction in triggering the process of AD dementia. It is widely proven that neuroinflammation is a prominent feature in $\mathrm{AD}$ brains and that inflammatory responses play a significant role in progression of the disease. Prolonged and spread activation of microglia in AD brain correlates with the extent of brain atrophy and cognitive decline. However the role of microlglia in the development of AD is controversial. There are some data about impairment of energy metabolism in astrocytes in $\mathrm{AD}$ and other neurodegenerative conditions.

Astrocytes play several important functions in the metabolism of the brain including intercompartmental turnover of amino acid neurotransmitters and energy substrates. Among others, these cells provide neurons with lactate, glutamine and aspartate for energy production as well as with the precursors for neurotransmitter. The end-feet of astrocytes occupy a strategically special location in brain between capillary endothelial cells and neurons. In addition, astrocytes as a member of the tripartite synapse remove efficiently neurotransmitters such as glutamate from the synaptic cleft and have important functions in regulating extracellular ion homeostasis. Due to the extensive contacts with both blood vessels and neurons astrocytes play a key role in the control of cerebral energy and transmitter metabolism. Astrocyte function and astrocyte-neuronal interactions are very important for synaptic 
plasticity. Thus impairment of astrocyte metabolism in various brain pathologies also has its negative influence on neuronal functions.

\section{Brain energy metabolism}

Particular cellular compartments of the brain differ markedly in their rates of energy generation and consumption. Among them, neurons constituting only $10 \%$ of the brain cells, consume up to $80 \%$ of its total energy output. Neuronal cells have no capacity to store any meaningful reserves of high energy compounds. Therefore, the effective functioning of neurons is dependent on the permanent supply of equivalent amounts of glucose and oxygen. About $60-70 \%$ of the energy produced in the neurons is consumed for the maintenance and restoration of the pre-and postsynaptic membrane potentials after the functional depolarization taking place with frequency from several to tens of Hz. Furthermore, the synthesis of neurotransmitters, particularly acetylcholine (ACh), also consumes fraction of pyruvate derived acetyl-CoA, a key substrate for tricarboxylic acid cycle (TCA). Neurotransmission requires a transmembrane lipid asymmetry and the constant rearrangement of phospholipids. The amount of energy consumed in these processes is constitutes about $25 \%$ of the total pool [1]. Therefore, the energy expenditures for maintenance metabolic activity of the brain are very high and can be a factor limiting the number of neurons that can be fully active at any given time [2].

Glucose from brain vascular compartment is transported across the blood brain barrier and astrocytes extensions by transporters GLUT1 of high-density and medium affinity for glucose $(\mathrm{Km} \mathrm{5-10} \mathrm{mmol/L).} \mathrm{Their} \mathrm{expression} \mathrm{in} \mathrm{endothelium} \mathrm{is} \mathrm{reduced} \mathrm{by} \mathrm{chronic} \mathrm{hyperglycemia} \mathrm{[3].}$ On the other hand, neurons on their plasma membranes contain high density of transporters GLUT3 of high affinity to glucose ( $\mathrm{Km} \mathrm{1-2} \mathrm{mmol/L),} \mathrm{expression} \mathrm{of} \mathrm{which} \mathrm{may} \mathrm{increase} \mathrm{during}$ chronic hypoglycemia [3-4]. In turn, astrocytes, take up glucose through the transporter GLUT1. The high rate of glucose uptake by neurons and astrocytes makes its concentration in extracellular spaces of the brain to be one third lower than in the blood plasma. Thus, under physiological conditions, the transport of glucose into neurons is the maximum a rate of about $6.5 \mu \mathrm{mol} / \mathrm{s}$ in the whole brain [3]. It should be noted that GLUT1 transporters are insensitive to hypoglycemia, whereas GLUT3 to hyperglycemia [5]. These properties make the transport of glucose into neurons optimized, which assures a relatively constant supply of this energy substrate, despite large fluctuations in blood glucose concentrations under physiological and pathological conditions.

An additional fraction of energy substrates is provided by astrocytes, which by their extensions take up the glucose directly from the circulation and display a high rate of glycolytic cycle. Therefore, they synthesize and release large amounts of lactate, which may be taken up by neurons through their monocarboxylic acids transporters MCT1 and MCT4. Lactate is transported into neurons serving as a source of pyruvate, the direct precursor of acetyl-CoA [6-7]. There are claims, that the lactate under certain physiologic and pathologic conditions may provide up to $25 \%$ of the energy in neurons [5,8-10]. In addition, high-fat diets, starvation, as well as diabetic ketoacidosis can activate uptake of $\mathrm{BHB}$, through the beta-hydroxybutyrate dehydrogenase- 
acetoacetyl-CoA synthetase-beta-ketothiolase steps. The level of BHB in extracellular compartment is about $3.4 \mathrm{mmol} / \mathrm{L}$. After being taken up into the cells by MCT1/MCT4 it becomes a source of acetyl-CoA independent of pyruvate dehydrogenase complex (PDHC) [4]. Therefore ketogenic diet is used to treat syndromes of congenital deficiency of PDHC, although the effectiveness of this treatment is limited [1,11-13]. Patients improvement is limited to the general conditions including alleviation of seizures. Deep losses of cognitive functions remain uncorrected. Hence, neither lactate nor ketoacids can't completely replace glucose as energy substrate for neurons.In this respect, there is no explanation why under in vitro conditions pyruvate/ lactate remain better energy/acetyl-CoA sources than the glucose $[9,14]$.

\section{Cholinergic neurons and their role in central nervous system}

Cholinergic neurons constitute only $1-10 \%$ of the total pool of neurons depending on the region of the brain, but are indispensable for its basic function-cognition. With other transmitter systems (glutamatergic, GABAergic etc.) they form structural networks for short-and longterm memory formation as well as multiple associative functions [15]. The cholinergic neurotransmission is linked with cognition, higher feelings, the analysis of visual stimuli, olfactory and auditory processes, sustain attention, recall previously stored memory traces and the regulation of behavior. The cholinergic system regulates cerebral blood flow and controls the level of activity of the cerebral cortex, including the sleep-wake cycle [30] $[15,17,30]$. It also modulates cognitive functions plasticity processes in the brain $[16,18]$. Cholinergic motor neurons innervating neuro-muscular junctions are indispensable for contraction of all groups of striated muscles [16,19].

The prevalence of neurodegenerative pathologies increases with age. Many of them, including Alzheimer's disease (AD) or Wernicke or hypoxic encephalopathies, are connected with decay of cholinergic innervation in the regions of brain cortex responsible for diverse cognitive functions. Post mortem examinations reveal decrease in their number, atrophy, loss of arborization and the reduction of the level and activity of cholinergic markers such as choline acetyltransferase (ChAT) vesicular acetylcholine transporter (VAChT) or high affinity choline uptake system (HACU). They are linked with the impairment of cholinergic neurotranssmition. They correlate with results of the cognitive status of the patients shortly before their death in a progressive physiological age-associated memory impairment and cognitive function [19-20]. Recent reports indicate that accelerated and excessive cholinergic neuron atrophy and loss of their connections are the main feature of cellular pathology underlying AD [21]. Reductions of the number of septal cholinergic neurons were reported to vary from $10 \%$ to $90 \%$ [22-23].

\section{Selective vulnerability of cholinergic neurons}

Cholinergic neurons compared to other types of neurons exhibit significantly higher sensitivity to various pathogenic agents $[7,16,24-26]$. Different groups of cholinergic neurons in the central 
nervous system are characterized by the different sensitivity to similar, harmful active signals and factors. In AD first of all cholinergic neurons of septum are found to be damaged. This type of neurons have nerve endings in the hippocampus and different regions of cerebral cortex. On the other hand, cholinergic interneurons in the striatum and motor neurons in anterior horns of medulla oblongata remain intact, sometimes to the final stages of the disease. Pathological changes were observed in the cholinergic terminals in medial temporal lobe [27]. Early, selective changes in cholinergic neurons are also observed in the olfactory cortex, amygdala, CA-1 region and subiculum. Recent studies have shown that early amyloid overload in the amygdalar regions was associated with appearance of neurofibrillary tangles inside the neurons. These areas of the brain are known to be responsible for the formation of declarative and long-term memory [28-30]. Abundant deposits of amyloid- $\beta(A \beta)$ also occur in the frontal, temporal and parietal lobes. In the final stages of $A D$ up to $60-65 \%$ losses of cholinergic neurons in different areas of the hippocampus, and the accumulation of neurofibrillary tangles in other neurons have been reported [24]. Abundance of neurofibrillary tangles correlated with gravity of clinical symptoms of dementia. On the contrary, the presence of senile plaques was also found in several older patients, who were free from cognitive deficits [31]. Selective neurodegeneration of specific areas of the hippocampus leads to the functional isolation and contributes to the short term memory impairment, which can be seen particularly in the initial stage of the disease. Variable sensitivity of brain regions rich in cholinergic neurons to neurodegeneration may be due to the influence of other regionally characteristic, diverse neurotransmitter networks, as well as the variable interactions with astrocytic and microglial cells. It can also result from phenotypic diversity of individual groups of cholinergic neurons. The underlying cause of the varying sensitivity of different groups of cholinergic neurons may be the level of their cholinergic neurotransmission, the presence of different classes of glutamatergic receptors as well as the frequency of their basic electrophysiological activity. Studies on different whole brain and cell lines indicate, that particular sensitivity of cholinergic neurons to cytotoxic stimuli may be due to the fact that they are using acetyl-CoA, not only, as the other group of neurons, to produce energy, but also for the synthesis of the neurotransmitter, which is ACh [7,26,32].

\section{Alzheimer's disease}

Alzheimer disease (AD) is one of the most common neurodegenerative diseases in elderly populations. It is estimated that 30 millions people are suffering from AD around the world. The number of cases of AD continues to grow, it is anticipated that the number of patients by 2050 will triplicate as a result of increasing longevity in modern societies.

$\mathrm{AD}$ is characterized by a decrease in the number of neurons and their interconnections, linked with progressive impairments of memory and cognitive functions, disorientation and the appearance of neurodegenerative alterations in affected areas of the brain. Disruption of axonal transport in cholinergic neurons is one of the earliest signs of AD observed both in humans and in experimental studies using transgenic mice [33]. The typical hallmark of AD is preferential loss of cholinergic neurons and their extensions in the olfactory bulbs, hippocampus, 
frontal, occipital and parietal lobes [34]. Differential sensitivity of between particular groups of cholinergic neurons may be due to their highly variable phenotypes as well as functional status (septal and motor neurons as an example) [35]. Clinical and animal studies demonstrated that loss of septal cholinergic neurons occurred well before those of other groups of neuronal and glial cells. Particular susceptibility of cholinergic neurons may be caused by the fact that in pathological neurodegenerative conditions, their demand for acetyl units for ACh synthesis overlaps with inhibition of PDHC [7,26,32]. This conclusion remains in accord with studies on human $\mathrm{AD}$ brains, that revealed a decrease of $\mathrm{PDHC}, \alpha$-ketoglutarate dehydrogenase (KDHC) and aconitase activities in areas affected by this pathology [7,35-36].

Accumulation of $\mathrm{A} \beta /$ senile plaques in extracellular compartment and hyperphosphorylated tau protein inside the neurons are characteristic histopathological findings in AD brains [37].

The process of $A \beta$ peptide accumulation and its polymerization under favorable conditions is very slow. It gave rise to the hypothesis that amyloidosis is just an outcome but not the cause of $\mathrm{AD}$ degeneration [38-40]. A $\beta$ synthesized mainly as 40 amino acid peptide, with minute fractions of 39, 41 and 43 amino acid peptides, all of none or limited neurotoxicity. The 42 aminoacid $A \beta$ is apparently most toxic peptide in its mono-and oligomeric forms [30,41-42]. Amyloid peptides are formed by proteolytic processing of amyloid precursor protein (APP) in sequential reactions catalysed by $\beta$-and $\gamma$-secretase, respectively. Amyloid polymers are thought to disrupt the neuronal cells through formation high flow uncontrollable Ca-cation channels in their plasma membranes [41-42]. That triggers intensive red-ox processes being the source of excessive amounts of free radicals. Peroxidation of membrane phospholipids disrupts ions transport across cell membranes, including calcium homeostasis and causes changes in the functioning of the cell membrane receptor proteins. Aggregation and polymerization of $A \beta$ peptide and the accumulation of paired helical filaments in neurons and the synaptic endings impairs axonal transport leading to degeneration and death of neurons.

Biochemical alterations observed in the AD brains are associated with decreased activities of enzymes involved in energy metabolism as well as in those responsible for the biosynthesis, release and breakdown of $\mathrm{ACh}$, such as ChAT, acetylcholine esterase (AChE), HACU or VAChT. The impairment of signal transduction processes caused by decreased densities in muscarinic $\left(\mathrm{M}_{\mathrm{AChR}}\right)$ and nicotinic $\left(\mathrm{N}_{\mathrm{AChR}}\right)$ receptors and inhibition of the ACh synthesis and quantal release were also reported $[7,30,42]$.

$\mathrm{AChE}$ is an enzyme present both in the axons and nerve ending of cholinergic neurons and in postsynaptic neurons in the cerebral cortex. Therefore its activity/level is also decreased in parallel with the loss of cholinergic neurons taking place in AD and other encephalopathies, [43-44]. These changes were also accompanied by impaired axonal transport, which is one of the earliest functional alterations in cholinergic neurons of AD brains [43]. The decrease of activities/levels different cholinergic markers were also observed post mortem in affected brain areas [45-46]. It gave rise to the suggestion that impairment of cholinergic neurons in AD may precede later stages of neurodegeneration process [30]. These observations support the hypothesis of the pivotal role of cholinergic dysfunction in the pathomechanisms of $\mathrm{AD}$ dementia. 


\section{Hypometabolism in Alzheimer's disease}

Energy homeostasis of the brain is a very complex process. This is due to the high sensitivity of neurons to metabolic stress, existence of the blood brain barrier, high-energy requirements of the brain, and finally due to limited reserves of energy precursor substrates. In AD an impairment of brain energy metabolism occurs, a process known as hypometabolism [1,47-48]. Studies with positron emission tomography (PET) using $\left[{ }^{18} \mathrm{~F}\right]$ fluorodeoxyglucose exhibit impaired glucose metabolism in brain regions of both sides in the temporal, parietal and cingulate cortex. The extent of these changes correlates with cognitive impairment in the affected patients. These changes are one of the well established diagnostic criteria for AD. PET combined with marking Pittsburgh blue (Pittsburgh compound-B) can specifically determine the $\mathrm{A} \beta$ deposits in the brain, so it is possible to diagnose the AD in its early stages [49-54]. Disturbances in glucose metabolism are associated with the reduction in the density of glucose transporters GLUT1 and GLUT3 in the neurons. Also activity of phosphofructokinase and glyceraldehyde-3-phosphate are diminished yielding suppression of the glycolytic metabolism, and facilitation of amyloidogenic transformation of APP and apoptosis [55-56].

However, the most important alteration in AD brains seems to be suppression of acetylCoA synthesis and TCA as well as the respiratory chain proteins. Reductions of PDHC, KDHC complex activities may be key factor in this pathomechanism due to reduction of acetyl-CoA synthesis and its utilization in TCA cycle, respectively. Studies of cholinergic septal neuronal cell lines have shown, that neurotoxins associated with AD pathomechanisms caused direct/instant inhibition of aconitase, PDHC, KDHC and suppressed synthesis and utilization of acetyl-CoA in mitochondria yielding increased mortality in septal cholinergic SN56 neuronal cells with high expression of the cholinergic phenotype $[7,32]$. One of the main changes observed an early stage of $\mathrm{AD}$ is the impairment of oxidative phosphorylation, which leads to decrease of electron transport in the respiratory chain, mainly in complex IV, which is associated with inhibition/decreased expression of cytochrome oxidase and ATP synthase. In this way, in the AD brains reduced of ATP level occurs. At this stage of the disease morphological changes of mitochondria were also observed. Disturbances in membrane fluidity and structure, reduction of the mitochondrial combs, density of mitochondria were also observed [57-59].

\section{Pivotal role of acetyl-CoA}

The principal, immediate source of acetyl-CoA in the brain is pyruvate formed from the glycolytic metabolism of glucose. The reaction of the oxidative decarboxylation of pyruvate supplying acetyl-CoA is catalyzed by PDHC, located in the mitochondria. More than $97 \%$ of acetyl residues via citrate synthase is metabolized to citrate and consumed in TCA cycle to produce the energy needed to restore the membrane potential during depolarization-repolarization cycles of several $\mathrm{Hz}$ frequency. Only 3\% of the pool of generated acetyl-CoA is used in the synthesis of ACh, which takes place in the cytoplasmic compartment [60-63]. However, 
under resting conditions acetyl-CoA molecules practically do not pass through the inner mitochondrial membrane into the cytoplasm. Therefore acetyl moiety for ACh synthesis must be transported to the cytoplasm through the intermediate metabolites, such as citrate, acetylL-carnitine, for which the inner mitochondrial membrane has a suitable transport systems [64]. In cytoplasm, acetyl-CoA is resynthesized from these compounds. It has been found, that in brain nerve terminals about $30-50 \%$ of acetyl-CoA pool is transported from the mitochondria to synaptoplasm, as citrate [65-67]. In cholinergic neurons and nerve terminals the metabolic flow through this pathway is facilitated by the preferential localization of ATP-citrate lyase (ACL) [67-70].

In various forms of dementia including $\mathrm{AD}$, thiamine deficiency, hypoxia or dialysis evoked encephalopathies in humans and animal models of dementia, loss of cognitive functions correlated with preferential deficits of cholinergic markers. Another striking feature in all of these pathologies was the decrease in energy metabolism in the affected regions of the brain $[7,21,35,57-58,71]$. The decreases in glucose metabolism and reduced stores of phosphocreatine and ATP have been shown during the life of the patients, by PET investigations [51-52,54]. This is confirmed by post mortem studies, which show that the cause of these changes may be decreased activity of PDHC, aconitase and KDHC in pathologically altered regions of the central nervous system [26,71-74]. These changes correlated with both the loss of cholinergic markers and the degree of degreased cognitive scores, before the death of the patient $[19,30,75]$. Studies on isolated cholinergic murine septal neuronal cell lines displayed strong inverse correlations between rates of cell death and PDHC activities or acetyl-CoA levels in their mitochondrial compartment under various neurodegenerative and neuroprotective conditions [7,40,76-80]. On the other hand, ChAT activity, ACh level and synthesis as well as quantal release correlated directly with levels of acetyl-CoA in cytoplasmic compartment of the cholinergic neurons [7,81].

\section{Acute and chronic neurotoxicity}

Cognitive deficits, the main clinical symptoms of cholinergic encephalopathies may in some cases combine with motor disability [82]. These changes correlate well with the degree of functional and structural losses of basal forebrain cholinergic neurons projecting axons to hippocampus and different cortical areas, motor neurons innervating different groups of striated muscles [45]. In these cases suppression of energy metabolism, correlates with losses of cholinergic markers in affected areas of brain cortex or spinal cord segments. Dysfunction of brain mitochondria is thought to be both the consequence of pathologic insults as well as a source of signals triggering neurodegeneration. Therefore, alterations in PDHC synthesized acetyl-CoA metabolism in the cholinergic neurons should be considered both as a source of disturbances in their transmitter functions and viability (Fig. 1) [7,32]. Several pathologic disturbances of aging brain cause excessive depolarization and overload of neuronal cells with $\mathrm{Ca}^{2+}$ and other divalent cations yielding diverse cytotoxic reactions. 


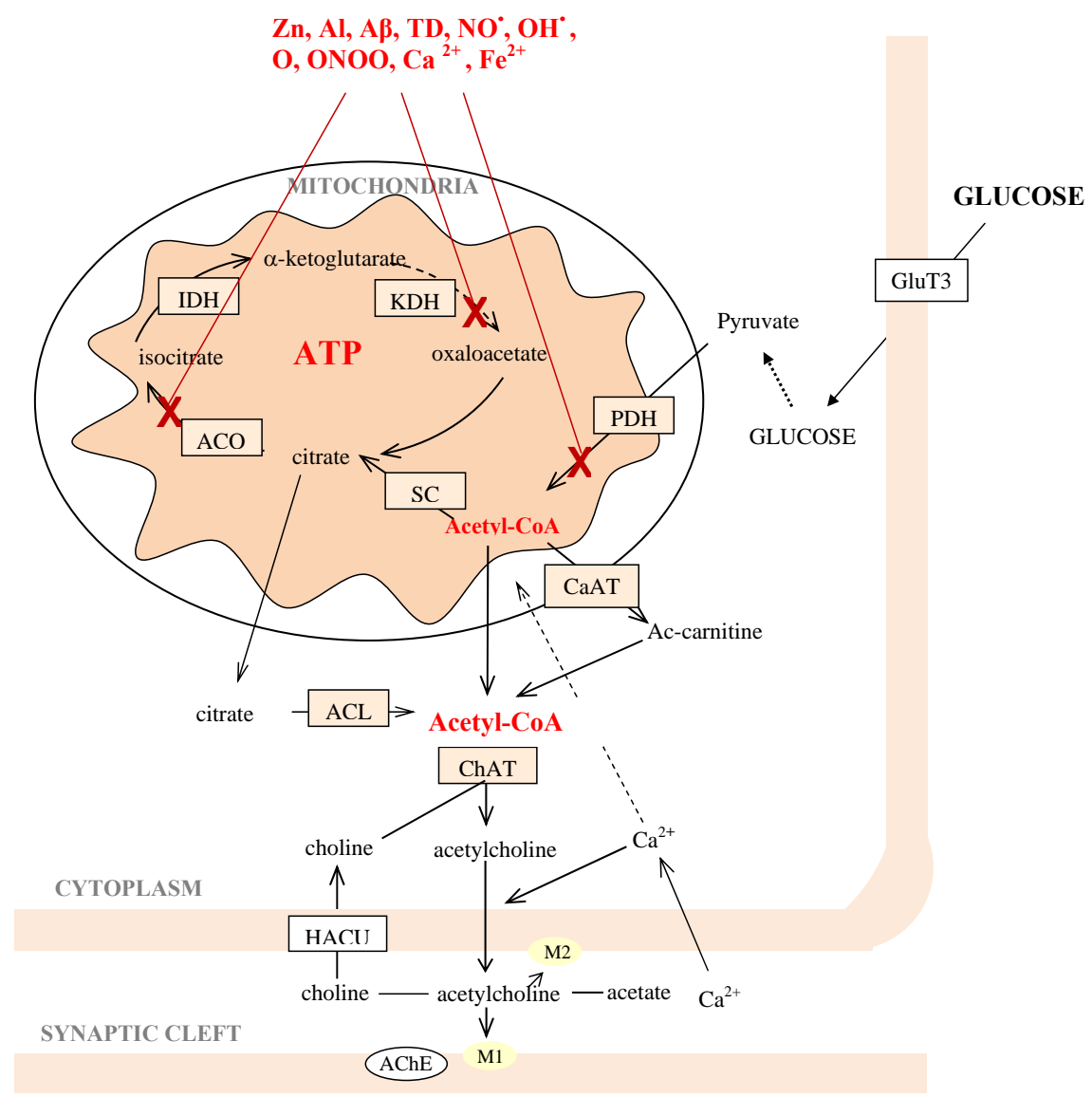

Figure 1. Putative neurotoxic signals affecting pathways acetyl-CoA and energy metabolism in brain cells and their specific interactions with cholinergic neurons.

Glutamateric neurotransmitter system constitutes 50\% of all brain neurons and synaptic terminals. Prolonged pathologic depolarization yields an excessive co-release of glutamate and Zn from brain terminals triggering action potentials through NMDA, AMPA receptors and other voltage gated $\mathrm{Ca}$ channels located on postsynaptic neurons including cholinergic ones [83-85]. They cause dysfunction of postsynaptic neurons that may lead to apoptosis and necrosis [86-87]. Energy deficits also inhibit uptake of glutamate by adjacent astrocytes, due to the down-regulation of EAA, GLAST and GLT1 transporters and inhibition of their glutamine synthetase [88]. Sustained elevations of glutamate and Zn levels within the synaptic clefts, yield prolonged depolarization of postsynaptic neurons, as well as astroglial and microglial cells [89]. The disruption of $\mathrm{Ca}^{2+}$ homeostasis affects enzymes linked with pathways involved in energy, neurotransmitter, and $\mathrm{NO}$ metabolism. The $\mathrm{Ca}^{2+}$ excess in the mitochondria 
compartment may lead to PDHC activity inhibition due to activation of PDH kinase. That may cause acetyl-CoA deficits in subcellular compartments of cholinergic neuronal cells [40,90-91]. During brain hypoxic/ischemic episodes the earliest event is excitotoxic activation caused by prolonged release of glutamate and $\mathrm{Zn}$ from glutaminergic nerve terminals. The excess of glutamate/Zn in the synaptic cleft results in, through multiple receptors and transporters, excitotoxic depolarization of postsynaptic neurons and adjacent glial cells as well. These alterations pave the road to subsequent chronic steps of neurodegeneration yielding characteristic histopathologic picture of amyloidosis- $\beta$ and tauopathy [92-93].

\section{Amyloid- $\beta$ toxicity}

It has been found that $\mathrm{AD}$ frequently combines with stroke and cerebral vessel thrombosis and other defects of capilary circulation [94]. Transient hypoxic and hypoperfusion conditions, frequent in eldery people brains, may also augment $A \beta$ accumulation by activation of $\gamma$ and $\beta$-secretases. They catalyze amyloidogenic cleavage of APP and increase A $\beta$ accumulation in extra-and intracellular compartments of the brain [95].

There is a common view that different extra-and intracellular deposits of $A \beta$ are the main cause of neuronal injury in the course of AD. Neurotoxic properties of $A \beta$ have been demonstrated in several experimental paradigms. It has been shown, that $A \beta$ added to the cell cultures inhibited the key enzymes of TCA cycle, as well as PDHC [77, 92,96]. It resulted in depletion of acetyl-CoA yielding supression of respiratory chain and ATP levels in affected neuronal cells $[76-77,97]$. These alterations could be aggravated by A $\beta$-evoked disruption of endogenous metal homeostasis, including calcium, iron, zinc and copper [98]. Accumulation of these metals as well as xenobiotic. Espesially aluminium, has been found in AD amyloid lesions. Each of these metals may aggravate inhibitory effects of $A \beta$ on oxidative/energy metabolism and cholinergic neurotransmission, yielding increased mortality of cholinergic neurons both in cultures and in brain tissue in situ [32]. A $\beta$ fibrilar polymers were reported to form high conductance Ca-channels in cell plasma membranes, with apparent impairment of energy metabolism and activation catabolic pathways [99-100]. Subtoxic levels of A $\beta$ were found to directly inhibit PDHC activity in brain nerve terminals [96]. Accumulation of extracellular $\mathrm{A} \beta$ aggravated suppressive effect of NGF mediated by $\mathrm{p} 75$ receptors abundantly expressed in septal cholinergic neurons, yielding different suppressive and neurotoxic reactions $[32,101]$. $\mathrm{A} \beta$ also facilitaed inflammatory responses of microglial cells, that promote neurodegenerative processes through excessive production of inflammatory cytokines [102]. However, a recent report reveals that $A \beta$ accumulation in sensitive regions of human cortex correlated neither with loss of cholinergic innervation nor with impairment of respective cognitive functions [103]. That supports earlier notions that $A \beta$ should be considered rather as an outcome than the cause of $\mathrm{AD}$ encephalopathy. Nevertheless, that does not rule out the possibility that accumulated $A \beta$ may combine with preceding cytotoxic signals, yielding augmentation of neurodegeneration processes. 


\section{Zinc neurotoxicity}

Zinc is an essential trace element for living organisms, being the component of active centers of about 300 enzymes and proteins including: carboxypeptidase, aspartate carbamoyltransferase, alcohol dehydrogenases, peroxide dismutase, zinc finger structures of transcription factors and several others [104-105]. It down-regulates the activity of NMDA receptors and other transporter proteins. As a crucial structural element in zinc-fingers, $\mathrm{Zn}$ is a regulator of transcription and other adaptative reactions of the organism [106-107]. It inhibits the opening of NMDA channels [108], that during sustained depolarization may take up the excess of this metal from-the synaptic cleft into the postsynaptic neurons [108].

Zinc concentration in synaptic vesicles of glutaminergic terminals may reach levels of few hundred $\mathrm{mmol} / \mathrm{L}$ as it forms complex with L-glutamate to assure isoosmolality of the vesicular fluid. In accordance with this the highest whole tissue concentration of $\mathrm{Zn}$, about 0.15 $\mathrm{mmol} / \mathrm{L}$, was found in the grey matter. During pathologic brain depolarization glutamate is released with zinc from glutaminergic terminals to synaptic clefts, where it can reach concentrations as high as $0.3 \mathrm{mmol} / \mathrm{L}$. Under physiological conditions $\mathrm{Zn}$ is quickly cleared from the synaptic cleft mainly by astrocytes and postsynaptic neurons.

There are three groups of proteins specifically regulating $\mathrm{Zn}$ distribution in brain cells. They include: ZnT1, located in the neuronal plasma membranes; ZnT2 in endoplasmic reticulum and ZnT3 in synaptic vesicles of nerve terminals [109]. These proteins are activated when zinc concentration in the cytoplasm is elevated. Apart from that, the neuron-specific membrane transporters Zip1, 4, 6 participate in zinc turnover [110]. Zip 1 and 4 remove zinc from the cell, whereas Zip 6 accumulates this cation in the intracellular compartment [111]. It is however not known how ZnTs functions combine with various Ca-channel/transporter activities in the regulation of $\mathrm{Zn}$ levels and compartmentalization in the neuronal cells.

Several pathologic conditions cause excessive release of zinc from presynaptic glutamatergic vesicles. High amounts of free $\mathrm{Zn}$ are taken-up by postsynaptic neurons and adjacent glial cells. There is no evidence whether large amounts of $\mathrm{Zn}$ can be released from other locations apart synaptic vesicles. There was increasing $\mathrm{Zn}^{2+}$ accumulation in degenerating neurons after excitotoxic stimulation of transgenic mice, lacking ZnT3 transporter that results in no zinc accumulation in vesicles [112]. Our earlier study revealed that high zinc accumulation in cultured neurons caused inhibition of key enzymes of energy metabolism [40,80]. Namely, $\mathrm{Zn}^{2+}$ directly inhibited PDHC and KDHC as well as aconitase activities which led to reduction of acetyl-CoA and ATP levels [40,80]. These Zn/glutamate induced energy deficits along with sustained depolarization along may cause $\mathrm{Ca}$ and free radical overloads. That triggers excessive synthesis of nitric oxide (NO), by nNOS and iNOS present in adjacent postsynaptic neuronal and glial cells, respectively. As a result excess of highly toxic peroxynitrite radicals accumulate in affected area. NO excess was reported to cause irreversible inhibition of aconitase and isocitrate dehydrogenase and the reversible one PDHC and KDHC [32,77,98]. These effects apparently aggravated cytotoxic effects of $\mathrm{Zn}$, triggering vicious cycle of cholinergic neurodegeneration [76,80-81]. There are evidences that aberrant $\mathrm{Zn}$ homeostasis is involved in the pathogenesis of $\mathrm{AD}$ [113]. Zn may be directly involved in the process of 
amyloidogenesis as APP protein was found to contain Zn binding motif [113] located within the cysteine-rich region of its ectodomain. This points out that $\mathrm{Zn}$ may play a role in yet unknown functions of APP.

High dietary intake of Zn significantly increased the Zn and APP levels in transgenic APP/P1 mouse brains. It also enhanced amyloidogenic cleavage of APP protein both under in vivo and in vitro conditions [114]. In mouse brain $\mathrm{Zn}$ inhibited $\alpha$-sectetase activity, elevating the $\beta$ and $\gamma$-secretase activities promoting accumulation of $A \beta(1-40)$, the main component of $A \beta$ plaques $[108,115]$. There was accompanied by the impairment of learning capacity in the Morris water maze test [114]. Zinc cytotoxic effects were observed not only in AD but also in several other brain pathologies including: epilepsy, mechanical trauma, ischemic stroke, hypoglycemia, hypoxia, thiamine deficits and other inherited or acquired metabolic blocks [115].

Besides, chronic pathological conditions may down-regulate expression of different classes of $\mathrm{ZnT}$ in astrocytes. In the same conditions $\mathrm{Zn}$ may be released to perisynaptic compartments [116]. Hence, $\mathrm{Zn}$ excitotoxicity would not be caused by overall increase of its concentration in the brain, but by its aberrant redistribution between different extra-and intracellular compartments of the brain [117].

Increased $\mathrm{Zn}$ concentrations in extracellular space may induce oligomerization of $A \beta$, aggravating its cytotoxic effect in $\mathrm{AD}$ brains. That is why short-time elevation of $\mathrm{Zn}$ concentrations in extracellular fluid (ECF) might trigger the long-term amyloidogenetic process. These signals were found to exert negative influence on cholinergic neurons that are responsible for cognitive functions and short-time memory formation [32]. It seems that high expression of the cholinergic phenotype in neurons (SN56) of septal origin makes them particularly susceptible to Zn-cytotoxic signaling $[7,40,80]$.

There was also reported that xenobiotic metal $\mathrm{Al}$ may also accumulate in the brains in agedependent manner [118-119]. It could inhibit calcium channels and $\mathrm{Na} / \mathrm{Ca}$ exchanger in mitochondrial membranes what might increase mitochondrial and decrease cytoplasmic calcium levels in nerve terminals and cholinergic neuronal cells [32,74]. All these pathogens either alone or in combination were found to cause the decrease acetyl-CoA synthesis in neuronal mitochondria and reduction of energy production yielding increased cholinergic neuron susceptibility to degeneration $[32,80]$. In addition, lowering the cytoplasmic level of calcium could reduce direct transport of acetyl-CoA from mitochondria to cytoplasm through permeability transition pores (PTP) [32,74]. Shortages of acetyl-CoA in cytoplasmic compartment cause inhibition of acetylcholine synthesis and release [40].

On the other hand, primary or secondary $\mathrm{Zn}$ deficits could also induce neurodegenerative brain injury. Such conditions were found in the elderly people who maintained themselves on Zn-deficient diet [41]. Some life periods such as intensive growth, pregnancy, lactation, intensive physical exercises increase demand for $\mathrm{Zn}$ facilitating appearance of its deficits. That is why numerous therapeutical and schedules recommend taking supplements that contain Zn organic complexes: zinc bisglicine, or zinc bisaspartate. They are claimed to be safer in use than nonchelatable inorganic Zn salts. However, there is no convincing data that would 
support this claim. Zn deficits in experimental animals were reported to cause to have increased oxidative stress and/or had greater rate of lipid peroxidation [120].
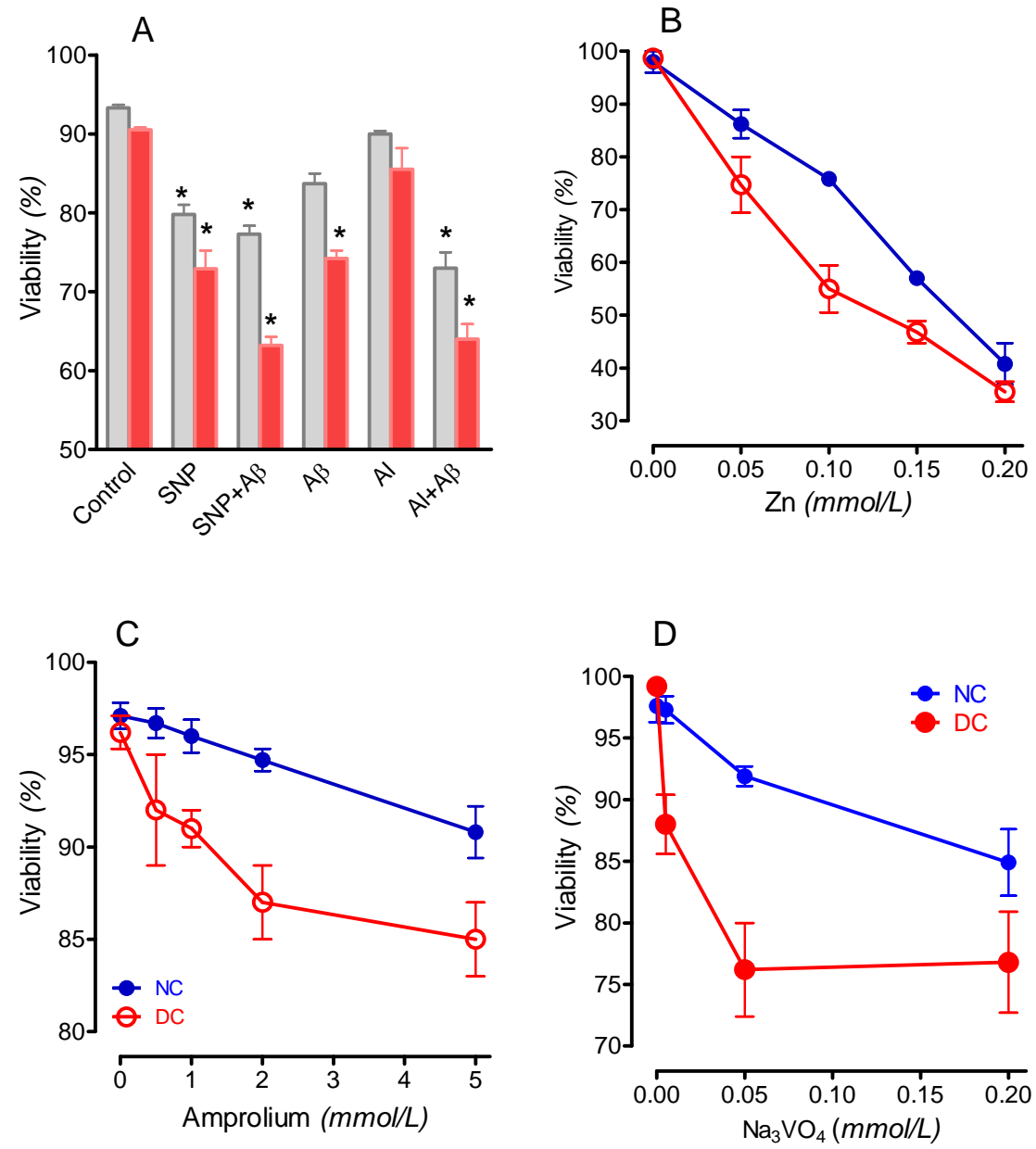

Figure 2. Differential neurotoxicities in nondifferentiated and differentiated cholinergic SN56 neuroblastoma cells. Recalculated from: [32,40,81,158-159].

\section{NO excess}

Glutamate-Zn evoked increases of $\left[\mathrm{Ca}^{2+}\right] /[$ calmodulin-Ca] in cytoplasmic compartments of postsynaptic neurons and adjacent glial cells activated nNOS and iNOS, respectively. It seems however, that only increased expression of Ca-independent iNOS in the microglial/astroglial 
cells may contribute significantly to neurodegeneration. It has been demonstrated, that only iNOS-dependent activation may elevate the NO levels in the brain up to low micromolar, pathologically relevant, concentrations [121]. In fact, bacterial lipopolysaccharides could induce several-fold increase of NO synthesis by microglia [121]. On the other hand, fraction of NO produced by nNOS/eNOS may reach levels two orders of magnitude lower, and is likely to play a physiologic roles of "volume transmitter" and guanyl cyclase activator [89]. Peroxynitrite radicals were found to react with wide range of intracellular biomolecules linked with energy and glycolytic metabolism and several regulatory and transport or neurotransmitter pathways, as well as with antioxidant systems. Excess of endogenous NO exerts rapid but reversible inhibition of cytochrome c oxidase and less potent one for other proteins of respiratory chain and ATP-synthetase, as well [122]. However, NO may also inhibit earlier steps of energy metabolism including: PDHC, aconitase, isocitrate NADP-dehydrogenase, as well as KDHC $[40,76,77]$. Other enzymes of TCA cycle: succinate dehydrogenase, fumarase, and malate dehydrogenase were not affected by these conditions. That could cause deficits of acetyl-CoA and ATP in NO/ONOO-exposed neuronal [32,76]. Cholinergic neurons with residual expression of the cholinergic phenotype appeared to be more resistant to NO neurotoxicity than those with high expression of the cholinergic phenotype, apparently due to negligible demand for acetyl-CoA to support ACh synthesis in the former.

Lipoic acid or acetyl-L-carnitine were found to exert positive effects on viability in NO or Znexposed cholinergic SN56 cells through preservation of acetyl-CoA availability in their mitochondrial and cytoplasmic compartments [32,77]. However, delay in cytoprotectant application markedly diminished their efficacy, apparently due to instant, irreversible inactivation of aconitase by $\mathrm{Zn}$ and NO/ONOO-[40,123]. ChAT appeared to be resistant to direct, acute exposition to NO-excess. However, its expression was adaptatively downregulated by chronic cytotoxic conditions decreasing acetyl-CoA provision into cytoplasmic compartment [124].

\section{Thiamine deficiency}

Thiamine pyrophosphate (TPP) is a cofactor for E1 subunits of PDHC and KDHC, that are key rate limiting steps regulating acetyl-CoA synthesis and its metabolic flux through TCA cycle, respectively [61,71,118,125-126]. Activities of these enzymes in the brain mitochondria are several times higher than in nonneuronal tissues, due to high demand for energy in this tissue. Therefore, thiamine pyrophosphate deficits (TD) evoked by chronic alcoholism, starvation or thiamine depleting diets caused dramatic clinical symptoms of motor, cognitive and metabolic disturbances in the form of Wernicke-Korsakoff encephalopathy, muscular dystonia, edema and lactic acidosis, with frequently fatal outcomes [125,127-128]. On the other hand, early supplementation of TPP deficient subjects with thiamine, reversed symptoms of these pathologies [129]. The majority of TD-evoked neurologic and cognitive disturbances may be explained by the impairment of cholinergic neurotransmission. In TD brains there are two major mechanisms that are responsible for dysfuctioning and loss of cholinergic neurons: the primary limitation of acetyl-CoA provision and excytotoxic Zn overload. The first one is caused 

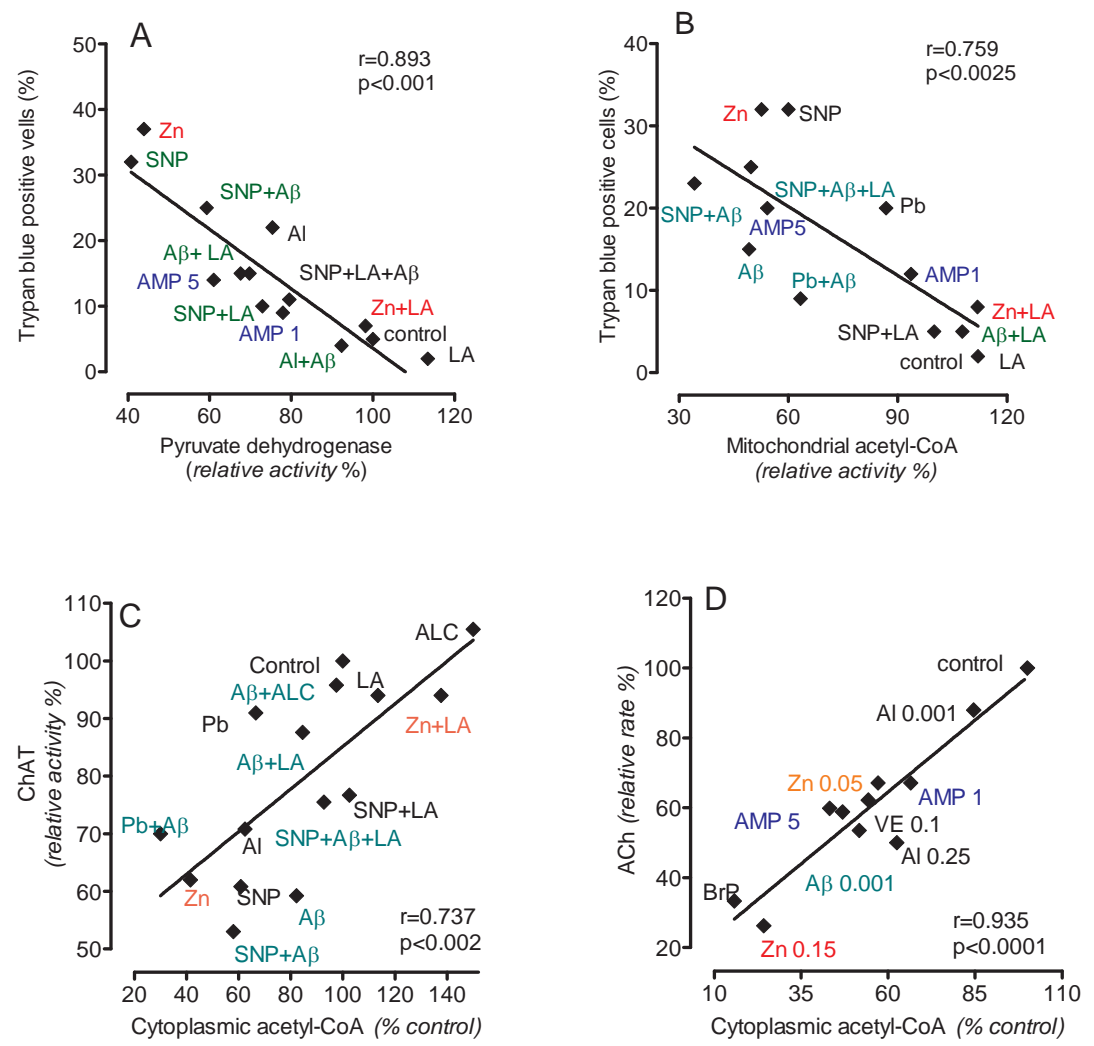

Figure 3. Existence of significant correlations between: intramitochondrial acetyl-CoA metabolism and cholinergic neuronal cell injury $(A B)$ and cytoplasmic acetyl-CoA levels and transmitter functions (CD) of cholinergic neuronal cells of septal origin. Data collected from: [32,40,81,124].

by the impaired synthesis of acetyl-CoA by PDHC, what strightly leads to the excytotoxic release of glutamate-Zn from energy depleted glutamatergic neurons [108]. In whole brain and cellular models of TD, the reduction of mitochondrial levels of acetyl-CoA correlated with losses of cholinergic markers and viability of the neurons [81,119,130-131].

The decreases of cytoplasmic acetyl-CoA in amprolium-induced TD SN56 cells and brain nerve terminals, from pyrythiamine treated rats, resulted from limited synthesis of this metabolite in the mitochondrial compartment by TD-deficient PDHC. In consequence, lower rates of ACh synthesis and its quantal release in TD cholinergic neurons positively correlated with decreased concentration of acetyl-CoA in their cytoplasmic compartment [81,130]. These findings fit to a general rule that the rate of ACh synthesis/release depends on the availability of acetyl$\mathrm{CoA}$ in cytoplasmic/synaptoplasmic compartment of cholinergic neurons, irrespective of the type of neurotoxic signal $[7,32]$. However, unlike for AD or other neurotoxic conditions, acute 
TD altered ChAT activity neither in pyrithiamine-rat brain synaptosomes nor in amproliumSN56 cells [132]. These data prove that, at least in early stages of TD, the structure of cholinergic neurons remained well preserved and that inhibition of ACh quantal release is exclusively due to the inhibition of acetyl-CoA provision to the site of its synthesis.

\section{Glia and neurotoxicity}

Astrocytes play several important functions in the metabolism of the brain including intercompartmental turnover of aminoacid neurotransmitters and energy substrates. They supply neurons with lactate, glutamine and aspartate for energy production neurotransmitter synthesis [133]. The end-feet of astrocytes occupy a strategic sites between capillary endothelial cells and neurons. In addition, astrocytes as a member of the tripartitie synapse remove efficiently neurotransmitters such as glutamate from the synaptic cleft and have important functions in maintenance of ion homeostasis in the extracellular compartments of the brain [134]. Due to the extensive contact with both blood vessels and neurons, astrocytes play the key role in the control of cerebral energy and transmitter metabolism. Astrocyte viability and astrocyte-neuronal interactions take part in processes of synaptic plasticity. Thus impairment in astrocyte metabolism in various brain pathologies also has its negative influence on neuronal functions.

There are some data about impairment of energy metabolism in astrocytes in AD and other neurodegenerative diseases [135]. However, most of them have been collected using isolated astroglial cells or whole brain models without taking into account subcellular distribution of energy metabolism. Therefore, like in the neuronal cells [7] putative aberrations of acetyl-CoA metabolism in the cytoplasmic and mitochondrial compartments of astrocytes, should be investigated in different models of $\mathrm{AD}$ and other cholinergic encephalopathies. The main role of astrocytes is to protect and support neurons. Astrocytes are capable to produce net lactate, L-glutamine and accumulate glycogen. They consume about $15-20 \%$ of the glucose in the brain $[136,137]$. Thanks to this they can deliver lactate to neurons, through monocarboxylate transporters MCT1, MCT 2. Lactate, after conversion to pyruvate may serve as an alternative to glucose source of acetyl-CoA under hypoglycaemic or hypoxic conditions. During physiologic activation of glutamatergic endings $\mathrm{Na}^{+}$dependent transport of glutamate into astrocytes by GLT1 and GLAST transporters was found to be enhanced. Subsequently glutamate was converted there to L-glutamine [136]. There are no Zip transporters on the surface of astrocyte's cellular membrane. Therefore uptake of zinc from synaptic cleft occurs through high density divalent metal transporters: DMT1. Except of Zn ions astrocytes may take up also iron and copper [138]. Apart from that, astrocytes contain high levels of metalothioneins (MTs). In consequence they can take up Zn from synaptic cleft and bind it forming complexes with MTs [139]. That is why impairment of astrocytes under cytotoxic conditions may limit their neuroprotective functions and indirectly facilitate neurodegenerative processes.

There are several therapeutic and preventive approaches to $\mathrm{AD}$ and other cholinergic encephalopathies of advanced age. However, now days only cholinomimetics and GABA- 
antagonists are approved for treatment of $\mathrm{AD}$ and related dementive disorders. They, however neither prevent nor slow down the progress of cognitive loses [102]. Other, therapeutic approaches such as choline supplementation, provision of acetyl-CoA precursors, or free radical scavengers, neurotrophin supply, antiinflamatory drugs application, inhibition of $A \beta$ synthesis or reduction of its overload appeared to be ineffective.

Neuroinflammation is one of principal pathomechanisms of AD which significantly contributes to the progress of the disease [102]. Prolonged and widely spread activation of microglia in $\mathrm{AD}$ brain correlates with the extent of brain atrophy and cognitive decline. However, the role of microlglia in the development of $\mathrm{AD}$ is a subject of discrepant reports. On one hand, microglial fagocytosis of $A \beta$ is belived to be a protective mechanism againts neurodegeneration [140]. Both atrocytes and microglia release both pro-and anti-inflammatory cytokines and prostaglandins, as well as oxygen, nitrosyl radicals. Cytokines through TLR-4 receptors were found to stimulate variety of intracellular signaling pathways that have been implicated in neuronal damage in AD. Therefore, people taking chronically nonsteroid anti-inflammatory drugs displayed lower prevalence of this pathology [141]. Microglial activation by many endogenous and signaling compounds such as L-glutamate, ATP, 7-ketocholesterol, cAMP were reported to cause inhibition of several enzymes of their energy metabolism [32,141]. Both $\mathrm{Zn}$ and $\mathrm{A} \beta$ oligomers are capable of microglia activation. This results in release of soluble neurotoxic compounds that compromise integrity of neurons and synapses [142]. Also Zn in rather low concentrations (30-50 micromol/L) activates microglia through mechanism dependent on activation of transcription factor NF-kappaB [143]. Simultaneously active compounds derived from activated microglia augment $\mathrm{Zn}$ release from glutamatergic neuronal endings what may accelerate neurodegenerative processes [144].

The activation of both astrocytes and microglial cells is associated with the induction of major proinflammatory pathways [145]. Gene expression profile analysis confirmed the prominent upregulation of genes associated with the immune/inflammatory pathways, including several chemokines and pro-inflammatory cytokines [146]. Activation the IL-1 $\beta$ pathway has been revealed both, in glial as well as in neuronal cells in brains of chronically epileptic rats [147]. Both the complement pathway and the plasminogen system are also activated within the hippocampus affected by multiple-sclerosis [148-149]. Both IL-1 $\beta$, complement components and plasminogen activators were found to increase the permeability of the blood brain barrier (BBB) $[150,151]$. Toll-like receptor (TLR) signaling pathways in brains affected by various pathologies such as epilepsy, ischemia or AD, may contribute to neuronal injury [152]. Moreover microRNAs (miRNA) also play a role in the regulation of the innate and adaptive immune responses. In particular, miR-146a, which can be induced by different pro-inflammatory stimuli such as IL- $1 \beta$ and TNF- $\alpha$, has been shown to critically modulate innate immunity through regulation of TLR signaling and cytokine responses [153]. Interestingly, this miRNA is upregulated in TLR as well as in experimental models of epilepsy. These observations suggest miRNA as potential targets to modulate inflammatory pathways.

Moreover activation of microglia is the well known source of nitric oxide and other reactive oxygen species (ROS) [154]. There are data showing that NO produced by activated microglia inhibits the activity KDHC [155]. 
Numberous data proved that prolonged activation of microglia leads to excessive secretion of NO, ROS and proinflamatory cytokines [156]. Lypopolysacharide (LPS) derived from bacteria exerts the capacity to activate microglial cells. In such conditions the cells secrete augmented levels of Il-1 $\beta$, Il-6, TNF- $\alpha$. TNF- $\alpha$ in nonactivated microglia is produced in insignificant concentration whereas in LPS-activated cells the level of its release is several times expanded [157]. Microglia may be also stimulated by $\mathrm{A} \beta$ what in consequence conducts to excessive release of TNF- $\alpha$, that becomes the neurotoxic factor. However some data reports that low Il-1 $\beta$ concentrations may have positive effect on highly differentiated cholinergic neurons by increasing the ChAT expression and activity in cholinergic neurons treated by neurotoxic concentrations of $A \beta$ [124]. In consequence the level of ACh was also elevated. Moreover these data also proved that added Il- $1 \beta$ reversed the inhibitory effect of cytotoxic factors on acetylCoA level in cytoplasmic compartment. These changes in cholinergic phenotype correlated well with cell viability and morphology. From the other hand Il-1 $\beta$-activation was completely inhibited by IL- 6 or TNF- $\alpha$.

The other data proves that in the cocultures of neuronal cells with microglial cells the last ones protect neurons from death caused by some cytotoxic factors such as elevated $\mathrm{Zn}$ or NO levels (Gul-Hinc et al. unpublished). The cytoprotective effect may be caused by the restoration by microglia the proper level of Il-6 in cholinergic neurons and restoration of the high activity of PDHC and acetyl-CoA level. From the other hand LPS-induced excessive release of TNF- $\alpha$ by microglia exerts the cytotoxic effect that is independent on acetyl-CoA level.

\section{Conclusions}

There is some data concerning the mechanism of cholinergic encephalopathies in particular Alzheimer disease. They are mainly focused on disturbances in A $\beta$ metabolism and only little of them reflect changes in energy metabolism particularly after various cytotoxic factors. However there is the existence of significant correlation between components of pyruvateacetyl-CoA-acetycholine pathway. Cytotoxic insults that are responsible for AD such as: $A \beta$, $\mathrm{Zn}, \mathrm{Al}, \mathrm{NOO}$, TD directly or indirectly inhibits the activity of PDHC and KDHC what leads to acetyl-CoA synthesis. Consequently, there is inhibition of activity of three carboxylic acid cycle what causes the development of neurodegenerative changes in brain. Characterictic feature of some neurodegenerative diseases in preferential loss of cholinergic neurons what correlates with the degree of energy metabolism inhibition. Some data proved that survival of cholinergic neurons is limited by the level of acetyl-CoA in mitochondrial compartment. Moreover it is independent in the reason. The particular susceptibility of cholinergic neurons to various cytotoxic insults is triggered by relative shortage of this metabolite in mitochondria and used for acetylcholine synthesis. That is why it might be said that PDHC activity strait determine acetyl-CoA level in mitochondria what limits its utilization for energy production and acetylcholine synthesis under cytotoxic insults. 

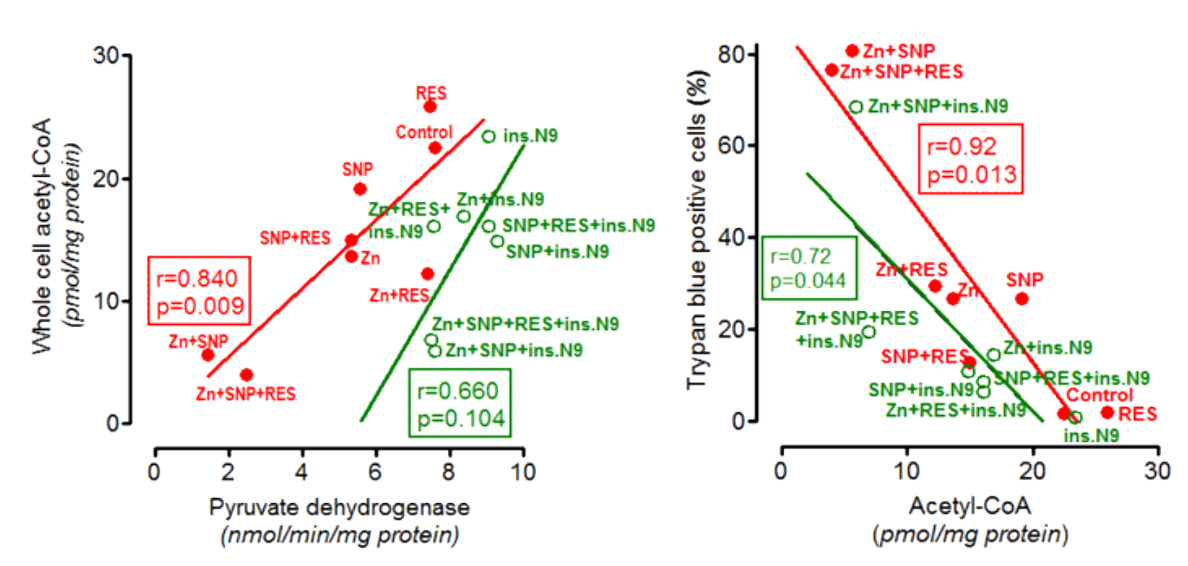

Figure 4. Parcrine effects of microglial N9 cells rescuing cholinergic SN56 neurons under excititocic conditions. A. Microglial effect preserving PDHC activity. B. Microglial effect decreasing mortality without affecting acetyl-CoA levels in cholinergic neurons. (Gul-Hinc, unpublished).

\section{Acknowledgements}

Supported by the Ministry of Research and Higher Education projects: NN401 1029937, IP 2010 035370 and IP 2011046071.

\section{Author details}

Agnieszka Jankowska-Kulawy, Anna Ronowska and Andrzej Szutowicz

Department of Clinical Biochemistry Medical University of Gdansk, Poland

\section{References}

[1] Cunnane S, Nugent S, Roy M, Courchesne-Loyer A, Croteau E, Tremblay S, Castellano A, Pifferi F, Bocti Ch, Paquet N, Begdouri H, Bentourkia M, Turcotte E, Allard M, Barberger-Gateau P, Fulop T, Rapoport S. Brain fuel metabolism, aging, and Alzheimer's disease. Nutrition 2011;27 3-20.

[2] Torrealdea FJ, Sarasola C, d'Anjou A. Energy consumption and information transmission in model neurons. Chaos, Solitions and Fractals 2009;40 60-68. 
[3] Duelli R, Kuschinsky W. Brain glucose transporters: relationship to local energy demand. News Physiol Sci 200;16 71-76.

[4] Simpson IA, Carruthers A, Vannucci SJ. Supply and demand in cerebral energy metabolism: the role of nutrient transporters. J Cereb Blood Flow Metab 2007;27 17661791.

[5] Barros LF, Deitmer JW. Glucose and lactate supply to the synapse. Brain Res Rev 2010; 63 149-159.

[6] Pierre K, Pellerin L. Monocarboxylate transporters in the central nervous system: distribution, regulation and function. J Neurochem 2005;94 1-14.

[7] Szutowicz A, Bielarczyk H, Jankowska-Kulawy A, Pawełczyk T, Ronowska A. Acetyl-CoA the key factor for survival or death of cholinergic neurons in course of neurodegenerative diseases. Neurochem Res 2013;38 1523-1542.

[8] Aubert A, Costalat R, Magistretti PJ, Pellerin L. Brain lactate kinetics: modeling evidence for neuronal lactate uptake upon activation. Proceedings of the National Academy of Science of the United States of America 2005;102(45) 16448-16453.

[9] Rasmussen P, Wyss MT, Lundby C. Cerebral glucose and lactate consumption during cerebral activation by physical activity in humans. FASEB J 2011;25 2865- 2873.

[10] Xiang Y, Shen J. Simultaneous detection of cerebral metabolism of different substrates by in vivo ${ }^{13} \mathrm{C}$ isotopomer MRS. J Neurosci Methods 2011;198 8-15.

[11] Freeman JM, Kossoff EH. Ketosis and the ketogenic diet, 2010: advances in treating epilepsy and other disorders. Adv Pediatr 2010;57 315-329.

[12] Leigh D. Subacute necrotizing encephalomyelopathy in an infant. J Neurol Neurosurg Psychiatry 1951;14 216.

[13] Uziel G, Ghezzi D, Zeviani M. Infantile mitochondria encephalopathy. Arch Dis Child Seminars in Fetal and Neonatal Medicine 2011;16 205-215.

[14] Herzog RI, Jiang L, Herman P, Zhao Ch, Sanganahalli BG, Mason GF, Hyder F, Rothman DL, Shervin RS, Behar KL. Lactate preserves neuronal metabolism and function following antecedent recurrent hypoglycemia. J Clin Invest 2013;123 1988-1998.

[15] Lucas-Meunier E, Fossier P, Baux G, Amar M. Cholinergic modulation of the cortical neuronal network. Pflugers Arch 2003;446 17-29.

[16] McKinney. Brain cholinergic vulnerability: relevance to behavior and disease. Biochem Pharmacol 2005;70 1115-1124.

[17] Sato A, Sato Y, Uchida S. Activation of the intracerebral cholinergic nerve fibers originating in the basal forebrain increase regional cerebral blood flow in the rat's cortex and hippocampus. Neurosci Lett 2004;361 90-93. 
[18] Schliebs R, Rossner S, Bigl V. Immunolesion by 192IgG-saporin of rat basal forebrain cholinergic system - a useful tool to produce cortical cholinergic dysfunction. Progr Brain Res 1996;109 253-264.

[19] Schliebs R, Arendt T. The significance of the cholinergic system in the brain during aging and in Alzheimer's disease. J Neural Transm 2006;113 1625-1644.

[20] Tucek S. Short-therm control of synthesis of acetylcholine. Prog Biophys Mol Biol 1993;60 59-69.

[21] Swaab DF, Bao AM. (Re-)activation of neurons in aging and dementia: lessons from the hypothalamus. Exp Gerontol 2011;46 178-184.

[22] Pakkenberg B, Gundersen HJ. Neocortical neuron number in humans: effect of sex and age. J Comp Neurol 1997;384 312-320.

[23] Swaab DF, Dubelaar EJ, Hofman MA, Scherder EJ, van Someren EJ, Verwer RW. Brain aging and Alzheimer's disease; use it or lose it. Prog Brain Res 2002;138 343373.

[24] Double KL, Reyes S, Werry EL, Halliday GM. Selective cell death in neurodegeneration: why are some neurons spared in vulnerable regions? Prog Neurobiol 2010;92 316-329.

[25] Szutowicz A, Tomaszewicz M, Jankowska A, Madziar B, Bielarczyk H. Mechanizmy selektywnej wrażliwości neuronów cholinergicznych na bodźce neurotoksyczne. Postępy Hig Med Dośw 1999;53 263-275.

[26] Szutowicz A, Tomaszewicz M, Jankowska A, Madziar B, Bielarczyk H. Acetyl-CoA metabolism in cholinergic neurons and their susceptibility to neurotoxic inputs. Metab Brian Dis 2000;15 29-44.

[27] Braak H, Braak E. Neuropathological staging of Alzheimer-related changes. Acta Neuropathol, 1991; 82 239-259.

[28] Mohamed NV, Herrou T, Plouffe V, Piperno N, Leclerc N. Spreading of tau pathology in Alzheimer's disease by cell-to-cell transmission. Eur J of Neurosci 2013;37 1939-1948.

[29] Rodriguez-Martin T, Cuchillo-Ibanez I, Noble W, Nyenya F, Anderton BH, Hanger DP. Tau phosphorylation affects its axonal transport and degeneration. Neurobiol of Aging 2013;34 2146-2157.

[30] Schliebs R, Arendt T. The cholinergic system in aging and neuronal degeneration. Behavioral Brain Res 2011;221 555-563.

[31] Driscoll I, Resnick SM, Troncoso JC. Impact of Alzheimer's pathology on cognitive trajectories in nondemended elderly. Ann Neurol 2006;60 688-695. 
[32] Szutowicz A, Bielarczyk H, Gul S, Ronowska A, Pawełczyk T, Jankowska-Kulawy A. Phenotype-dependent susceptibility of cholinergic neuroblastoma cells to neurotoxic inputs. Metab Brain Dis 2006;21 149-161.

[33] Herholz K, Weisenbach S, Kalbe E. Deficits of the cholinergic system in early AD. Neuropsychologia 2008;46 1642-1647.

[34] Serrano-Pozo A, Frosch MP, Masliah E, Hyman BT. Neuropathological alterations in Alzheimer disease. Cold Spring Harb Perspect Med 2011;1(1) 1-23.

[35] Bubber P, Haroutunian V, Fisch G, Blass JP, Gibson GE. Mitochondrial abnormalities in Alzheimer brain: mechanistic implications. Ann Neurol 2005;57 695-703.

[36] Sheu KF, Blass JP. The alpha-ketoglutarate dehydrogenase complex. Ann N Y Acad Sci 1999;893 61-78.

[37] Ouerfurth HW, LaFerla FM. Alzheimer's disease. N Engl J Med 2010;362 329-344.

[38] Cameron B, Landreth GE. Inflammation, microglia, and Alzheimer's disease. Neurobiol Dis 2010;37 503-509.

[39] Heneka MT, O’Banion MK, Terwel D, Kummer MP. Neuroinflammatory processes in Alzheimer's disease. J Neural Transm 2010;117 919-947.

[40] Ronowska A, Dyś A, Jankowska-Kulawy A, Klimaszewska-Łata J, Bielarczyk H, Romianowski P, Pawełczyk T, Szutowicz A. Short-term effects of zinc on acetylcholine metabolism and viability of SN56 cholinergic neuroblastoma cells. Neurochem Int 2010;56 143-51.

[41] Blennow K, de Leon M, Zetterberg H. Alzheimer disease. Lancet 2006;368 387- 403.

[42] Schliebs R. Basal forebrain cholinergic dysfunction in Alzheimer's disease - interrelationship with $\beta$-amyloid, inflammation and neurotrophin signaling. Neurochem Res 2005;30 895-908.

[43] Herholz K. Acetylcholine esterase activity in mild cognitive impairment and Alzheimer's disease. Eur J Nucl Med Mol Imaging 2008;35(1) 25-29.

[44] Jazi R, Lalonde R, Qian S, Strazielle C. Regional brain evaluation of acetylcholinesterase activity in PS1/A246E transgenic mice. Neurosci Res 2009;63 106-114.

[45] Pappas BA, Bayley PJ, Bui BK, Hansen LA, Thal LJ. Choline acetyltransferase activity and cognitive domain scores of Alzheimer's patients. Neurobiol Aging 2000;21 11-17.

[46] Terwel D, Bothmer J, Wolf E, Meng F, Jolles J. Affected enzymes activity in Alzheimer's disease are sensitive to antemortem hypoxia. J Neurol Sci 1998;161 47-56.

[47] Mosconi L. Glucose metabolism in normal aging and Alzheimer's disease: methodological and physiological considerations for PET studies. Clin Transl Imaging 2013, DOI 10.1007/s40336-013-0026-y. 
[48] Teipel S. Risk and resilience: a new perspective on Alzheimer's disease. Geriatr Ment Health Care 2013;1 47-55.

[49] Ballard C, Gauthier S, Corbett A, Brayne C, Aarsland D, Jones E. Alzheimer's disease. Lancet 2011;377 1019-1031.

[50] Britschgi M, Wyss-Coray T. Blood protein signature for the early diagnosis of Alzheimer disease. Arch Neurol 2009; 66 161-165.

[51] Herholz K. Amyloid PET: Its diagnostic potential compared to FDG. Med Nucléaire 2011;35 322-326.

[52] Kossowska B, Dudka I, Gancarz R, Antonowicz-Juchniewicz J. Analiza proteomiczna profili białkowych w niektórych stanach patologicznych ludzkiego organizmu. Postępy Hig Med Dośw 2009;63 549-563.

[53] Mosconi L, Brys M, Glodzik-Sobanska L, De Santi S, Rusinek H, de Leon J. Early detection of Alzheimer's disease using neuroimaging. Exp Gerontol 2007;42 129- 138.

[54] Price JC, Klunk WE, Lopresti BJ, Lu X, Hoge JA, Ziolko ST, Holt DP, Meltzer CC, DeKosky ST, Mathis CA. Kinetic modeling of amyloid binding in humans using PET imaging and Pittsburgh Compound-B. J Cereb Blood Flow Metab 2005;25 1528-1547.

[55] Liu Y, Iqbal K, Grundke-Iqbal I, Gong ChX. Decreased glucose transporters correlate to abnormal hyperphosphorylation of tau in Alzheimer disease. FEBS Lett 2008;582 359-364.

[56] Mazzola JL, Sirover M. Subcellular alteration of glyceraldehyde-3-phosphate dehydrogenase in Alzheimer's disease fibroblasts. J Neurosci Res 2003;71 279-285.

[57] Ferreira IL, Resende R, Ferreiro E, Rego AC, Pereira CF. Multiple deficits in energy metabolism in Alzheimer's disease. Curr Drug Targets 2010;11 1-14.

[58] Maruszak A, Żekanowski C. Mitochondrial dysfunction and Alzheimer's disease. Prog Neuropsychopharmacol Biol Psychiatry 2011;35 320-330.

[59] Tereni B, Boada J, Portero-Otin M, Pamplona R, Ferrer I. Mitochondrial ATP-synthase in the entorhinal cortex is a target of oxidative stress at stages I/II of Alzheimer's disease pathology. Brain Pathol 2010;20 222-233.

[60] Gibson GE, Jope R, Blass JP. Decreased synthesis of acetylcholine accompanying impaired oxidation of pyruvic acid in rat brain minces. Biochem J 1975;148 17-23.

[61] Lefresne P, Guyenet P, Głowiński J. Acetylcholine synthesis from $\left[2-{ }^{14} \mathrm{C}\right]$ pyruvate in rat striatal slices. J Neurochem 1973;20 1083-1097.

[62] Lefresne P, Hamon N, Beaujouan C, Głowiński J. Origin of acetyl moiety of acetylcholine synthesized in rat striatal synaptosomes. Biochimie 1977;59 197-215.

[63] Tucek S. Acetylcoenzyme-A and the synthesis of acetylcholine in neurons. Review of recent progress. Gen Physiol Biophys 1983;2 313-324. 
[64] Srere PA. The molecular physiology of citrate. Nature, Lond 1965;766-770.

[65] Gibson GE, Shimada M. Studies on the metabolic pathway of the acetyl group for acetylcholine synthesis. Biochem Pharmacol 1980;29 167-174.

[66] Szutowicz A, Stępień M, Łysiak W, Angielski S. Effect of (-)hydroxycitrate on the activities of ATP citrate lyase and the enzymes of acetyl-CoA metabolism in rat brain. Acta Biochim Pol 1976;22 227-234.

[67] Szutowicz A, Łysiak W, Angielski S. The effect of (-)hydroxycitrate on pyruvate metabolism in rat brain synaptosomes. J Neurochem 1977;29 375-378.

[68] Szutowicz A, Bielarczyk H, Łysiak W. The role of citrate derived from glucose in the acetylcholine synthesis in rat brain synaptosomes. Int J Biochem 1981a;13 887-892.

[69] Szutowicz A, Stępień M, Piec G. Determination of pyruvate dehydrogenase and acetyl-CoA synthase activities using citrate synthase. Anal Biochem 1981b;115 81-87.

[70] Szutowicz A, Tomaszewicz M, Bielarczyk H. Disturbances of acetyl-CoA, energy and acetylcholine metabolism in some encephalopathies. Acta Neurobiol Exp 1996;56 323-339.

[71] Bubber P, Ke ZJ, Gibson GE. Tricarboxylic acid cycle enzymes following thiamine deficiency. Neurochem Int 2004;45 1021-1028.

[72] Butterworth RF, Giguere JF, Besnard AM. Activities of thiamine-dependent enzymes in two experimental models of thiamine-deficiency encephalopathy: 1 . The puryvate dehydrogenase complex. Neurochem Res 1985;10 1417-1428.

[73] Szutowicz A, Bielarczyk H, Skulimowska H. Effect of dichloroacetate on acetyl-CoA content and acetylcholine synthesis in rat brain synaptosomes. Neurochem Res 1994;19(9) 1107-1112.

[74] Szutowicz A, Bielarczyk H, Kisielevski Y, Jankowska A, Madziar B, Tomaszewicz M. Effects of aluminium and calcium on acetyl-CoA metabolism in rat brain mitochondria. J Neurochem 1998;71(6) 2447-2453.

[75] Niewiadomska G, Baksalerska-Pazera M, Riedel G. The septo-hippocampal system, learning and recovery of function. Prog Neuropsychopharmacol Biol Psychiatry 2009;33(5) 791-805.

[76] Bielarczyk H, Jankowska A, Madzar B, Matecki A, Michno A, Szutowicz A. Differential toxicity of nitric oxide, aluminium and amyloid beta peptide in SN56 cholinergic cells from mouse septum. Neurochem Int 2003;42 323-331.

[77] Bielarczyk H, Gul S, Ronowska A, Bizon-Zygmanska D, Pawełczyk T, Szutowicz A. RS-alpha-lipoic acid protects cholinergic cells against sodium nitroprusside and amyloid-beta neurotoxicity through restoration of acetyl-CoA level. J Neurochem 2006;98 1242-51. 
[78] Jankowska A, Blusztajn JK, Szutowicz A. Activities of enzymes of acetyl-CoA and acetylcholine metabolism in SN56 hybrid cholinergic cell line differentiated by dibutyryl cyclic AMP and all-trans retinoic acid. Folia Neuropathol 1997;35 247-249.

[79] Jankowska A, Madziar B, Tomaszewicz M, Szutowicz A. Acute and chronic effects of aluminum on acetyl-CoA and acetylcholine metabolism in differentiated and nondifferentiated SN56 cholinergic cells. J Neurosci Res 2000;62 615-22.

[80] Ronowska A, Gul-Hinc S, Bielarczyk H, Pawełczyk T, Szutowicz A. Effects of zinc on SN56 cholinergic neuroblastoma cells. J Neurochem 2007;103(3) 972-83.

[81] Bizon-Zygmańska D, Jankowska-Kulawy A, Bielarczyk H, Pawełczyk T, Ronowska A, Marszałł M, Szutowicz A. Acetyl-CoA metabolism in amprolium-evoked thiamine pyrophosphate deficits in cholinergic SN56 neuroblastoma cells. Neurochem Int 2011;59, 208-216.

[82] Crochemore C, Peña-Altamira E, Virgili M, Monti B, Contestabile A. Disease-related regressive alterations of forebrain cholinergic system in SOD1 mutant transgenic mice. Neurochem Int 2005;(5) 357-68.

[83] Frederickson CJ, Maret W, Cuajungco MP. Zinc and excitotoxic brain injury: a new model. Neuroscientist 2004;10(1) 18-25.

[84] Hynd MR, Scott HL, Dodd PR. Glutamate-mediated excitotoxicity and neurodegeneration in Alzheimer's disease. Neurochem Int 2004;45(5) 583-95.

[85] Mocchegiani E, Bertoni-Freddari C, Marcellini F, Malavolta M. Brain, aging and neurodegeneration: role of zinc ion availability. Prog Neurobiol 2005;75(6) 367-90.

[86] Supnet C, Bezprozvanny I. Neuronal calcium signaling, mitochondrial dysfunction, and Alzheimer's disease. J Alzheimers Dis 2010;20,Suppl2 487-98.

[87] Yu JT, Chang RC, Tan L. Calcium dysregulation in Alzheimer's disease: from mechanisms to therapeutic opportunities. Prog Neurobiol 2009;89(3) 240-55.

[88] Jhala SS, Hazell AS. Modeling neurodegenerative disease pathophysiology in thiamine deficiency: consequences of impaired oxidative metabolism. Neurochem Int 2011;58(3) 248-60.

[89] Steinert JR, Chernova T, Forsythe ID. Nitric oxide signaling in brain function, dysfunction, and dementia. Neuroscientist 2010;16(4) 435-52.

[90] Lai JC, DiLorenzo JC, Sheu KF. Pyruvate dehydrogenase complex is inhibited in calcium-loaded cerebrocortical mitochondria. Neurochem Res 1988;13(11) 1043-8.

[91] Malloch GD, Munday LA, Olson MS, Clark JB. Comparative development of the pyruvate dehydrogenase complex and citrate synthase in rat brain mitochondria. Biochem J 1986;15 238(3) 729-36. 
[92] Selkoe DJ. Amyloid beta-protein precursor: new clues to the genesis of Alzheimer's disease. Curr Opin Neurobiol 1994;4(5) 708-16.

[93] Sensi SL, Paoletti P, Bush AI, Sekler I. Zinc in the physiology and pathology of the CNS. Nat Rev Neurosci 2009;10(11) 780-91.

[94] Torre JC. Alzheimer's disease prevalence can be lowered with non-invasive testing. J Alzheimers Dis 2008;14(3) 353-9.

[95] Guglielmotto M, Tamagno E, Danni O: Oxidative stress and hypoxia contribute to Alzheimer's disease pathogenesis: two sides of the same coin. The Scientific World J 2009;9 781-791.

[96] Hoshi Y, Hazeki O, Kakihana Y, Tamura M. Redox behavior of cytochrome oxidase in the rat brain measured by near-infrared spectroscopy. J Appl Physiol 1997;83 1842-81.

[97] Pereira C, Santos MS, Oliveira C. Involvement of oxidative stress on the impairment of energy metabolism induced by A beta peptides on PC12 cells: protection by antioxidants. Neurobiol Dis 1999;6(3) 209-19.

[98] Sensi SL, Yin HZ, Weiss JH. Glutamate triggers preferential $\mathrm{Zn}^{2+}$ flux through $\mathrm{Ca}^{2+}$ permeable AMPA channels and consequent ROS production. Neuroreport $1999 ; 10(8)$ 1723-1727.

[99] Berridge MJ. Calcium signalling and Alzheimer's disease. Neurochem Res 2011;36(7) 1149-56.

[100] Ueda K, Shinohara S, Yagami T, Asakura K, Kawasaki K. Amyloid-protein potentiates $\mathrm{Ca}^{2+}$ influx through L-type voltage-sensitive $\mathrm{Ca} 2+$ channels: a possible involvement of free radicals. J Neurochem 1997;68 265-271.

[101] Coulson EJ. Does the p75 neurotrophin receptor mediate A $\beta$-induced toxicity in Alzheimer's disease? J Neurochem 2006; 98 654-660.

[102] Mizuno T. The biphasic role of microglia in Alzheimer's disease. Int J Alzheimers Dis 2012;37846 1-9.

[103] Furst AJ, Rabinovici GD, Rostomian AH, Steed T, Alkalay A, Racine C, Miller BL, Jagust WJ. Cognition, glucose metabolism and amyloid burden in Alzheimer's disease. Neurobiol Aging 2012;33(2) 215-25.

[104] Fernandez LL, de Lima MN, Scalco F, Vedana G, Miwa C, Hilbig A, Vianna M, Schröder N. Early post-natal iron administration induces astroglial response in the brain of adult and aged rats. Neurotox Res 2011; 20(2) 193-9.

[105] Vallee BL, Falchuk KH. Zinc and gene expression. Philos Trans R Soc Lond B Biol Sci 1981;294(1071) 185-97. 
[106] Imanishi M, Imamura Ch, Higashi C, Yan W, Negi S, Futaki S, Sugiura Y. Zinc finger-zinc finger interaction between the transcription factors, GATA-1 and Sp1. Biochemical and Biophysical Research Communications 2010;400 4 625-630.

[107] Nagaoka M, Sugiura Y. Artificial zinc finger peptides: creation, DNA recognition, and gene regulation. J Inorg Biochem 2000;82(1-4) 57-63.

[108] Takeda A. Zinc signaling in the hippocampus and its relation to pathogenesis of depression. Mol Neurobiol 2011;44(2) 166-74.

[109] Colvin RA. Characterization of a plasma membrane zinc transporter in rat brain. Neurosci Lett 1998;247(2-3) 147-50.

[110] Guerinot ML. The ZIP family of metal transporters. Biochim Biophys Acta 2000;1465(1-2) 190-8.

[111] Szewczyk B, Pałucha-Poniewiera A, Poleszak E, Pilc A, Nowak G. Investigational NMDA receptor modulators for depression. Expert Opin Investig Drugs 2012;21(1) 91-102.

[112] Lee SH, Huang JW, Hung KY, Leu LJ, Kan YT, Yang CS, Chung Wu D, Huang CL, Chen PY, Chen JS, Chen WY. Trace Metals' abnormalities in hemodialysis patients: relationship with medications. Artif Organs 2000;24(11) 841-4.

[113] Maynard C, Bush A, Masters C, Cappai R, Li Q. Metals and amyloid-beta in Alzheimer's disease. Int J Exp Pathol 2005;86 147-159.

[114] Wang CY, Wang T, Zheng W, Zhao BL, Danscher G, Chen YH, Wang ZY. Zinc overload enhances APP cleavage and A $\beta$ deposition in the Alzheimer mouse brain. PLoS One 2010;5(12) e15349.

[115] Takeda A. Insight into glutamate excitotoxicity from synaptic zinc homeostasis. Int J Alzheimers Dis 2010;Vol. 2011, Article ID: 491597.

[116] Bertoni-Freddari C, Fattoretti P, Casoli T, Di Stefano G, Solazzi M, Perna E, De Angelis $C$. Reactive structural dynamics of synaptic mitochondria in ischemic delayed neuronal death. Ann N Y Acad Sci 2006;1090 26-34.

[117] Gil-Bea FJ, García-Alloza M, Domínguez J, Marcos B, Ramírez MJ. Evaluation of cholinergic markers in Alzheimer's disease and in a model of cholinergic deficit. Neurosci Lett 2005;375(1) 37-41.

[118] Szutowicz A: Aluminum, NO, and nerve growth factor neurotoxicity in cholinergic neurons. J Neurosci Res 2001;66 1009-1018.

[119] Szutowicz A, Jankowska-Kulawy A, Bielarczyk H. Disturbances in acetyl-CoA metabolism. A key factor in pre clinical and overt thiamine deficiency encephalophaty. Food and Nutritional Components in Focus: Chemistry, Analysis, Function and Effects, The Royal Society of Chemistry, edited by professor Victor Preedy, Chapter 33, 553-571, 2013a. 
[120] Taysi S, Cikman O, Kaya A, Demircan B, Gumustekin K, Yilmaz A, Boyuk A, Keles M, Akyuz M, Turkeli M. Increased oxidant stress and decreased antioxidant status in erythrocytes of rats fed with zinc-deficient diet. Biol Trace Elem Res 2008;161-7.

[121] Doherty GH. Nitric oxide in neurodegeneration: potential benefits of non-steroidal anti-inflammatories. Neurosci Bull 2011;27(6) 366-82.

[122] Moncada S, Bolaños JP. Nitric oxide, cell bioenergetics and neurodegeneration. J Neurochem 2006;97(6) 1676-89.

[123] Paradies G, Petrosillo G, Paradies V, Ruggiero FM. Mitochondrial dysfunction in brain aging: role of oxidative stress and cardiolipin. Neurochem Int 2011;58(4) 447-57.

[124] Bielarczyk H, Jankowska-Kulawy A, Gul S, Pawełczyk T, Szutowicz A. Phenotype dependent differential effects of interleukin-1beta and amyloid-beta on viability and cholinergic phenotype of T17 neuroblastoma cells. Neurochem Int 2005;47(7) 466-73.

[125] Gibson GE, Starkov A, Blass JP, Ratan RR, Beal MF. Cause and consequence: mitochondrial dysfunction initiates and propagates neuronal dysfunction, neuronal death and behavioral abnormalities in age-associated neurodegenerative diseases. Biochim Biophys Acta 2010;1802(1) 122-34.

[126] Szutowicz A, Tomaszewicz M, Bielarczyk H. Key role of acetyl-CoA in cytoplasm of nerve terminals in disturbances of acetylcholine metabolism in brain. Folia Neuropathol 1997;35(4) 241-3.

[127] Anzalone S, Vetreno RP, Ramos RL, Savage LM. Cortical cholinergic abnormalities contribute to the amnesic state induced by pyrithiamine-induced thiamine deficiency in the rat. Eur J Neurosci 2010;32(5) 847-58.

[128] Butterworth RF, Spahr L, Fontaine S, Layrargues GP. Manganese toxicity, dopaminergic dysfunction and hepatic encephalopathy. Metab Brain Dis 1995;10(4) 259-67.

[129] Bettendorff L. Thiamine homeostasis in neuroblastoma cells. Neurochem Int 1995;26(3) 295-302.

[130] Jankowska-Kulawy A, Bielarczyk H, Pawełczyk T, Wróblewska M, Szutowicz A. Acetyl-CoA and acetylcholine metabolizm in nerve terminal compartment of thiamine deficient rat brain. J Neurochem 2010;115 333-42.

[131] Jankowska-Kulawy A, Bielarczyk H, Pawełczyk T, Wróblewska M, Szutowicz A. Acetyl-CoA deficyt in braim mitochondria in experimental thiamine deficiency encephalopathy. Neurochem Int 2010a;57 851-856.

[132] Zhao N, Zhong C, Wang Y, Zhao Y, Gong N, Zhou G, Xu T, Hong Z. Impaired hippocampal neurogenesis is involved in cognitive dysfunction induced by thiamine deficiency at early pre-pathological lesion stage. Neurobiol Dis 2008;29(2) 76-85. 
[133] Grass D, Pawlowski PG, Hirrlinger J, Papadopoulos N, Richter DW, Kirchhoff F, Hülsmann S. Diversity of functional astroglial properties in the respiratory network. J Neurosci 2004;11 1358-65.

[134] Allen NJ, Barres BA. Neuroscience: Glia-more than just brain glue. Nature 2009;457(7230) 675-7.

[135] Gibbs ME, Gibbs Z, Hertz L. Rescue of $A \beta(1-42)$-induced memory impairment in day-old chick by facilitation of astrocytic oxidative metabolism: implications for Alzheimer's disease. J Neurochem 2009;109 Suppl 1 230-6.

[136] McKenna MC, Waagepetersen HS, Schousboe A, Sonnewald U. Neuronal and astrocytic shuttle mechanisms for cytosolic-mitochondrial transfer of reducing equivalents: current evidence and pharmacological tools. Biochem Pharmacol 2006;14,71 399-407.

[137] Jakoby P, Schmidt E, Ruminot I, Gutiérrez R, Barros LF, Deitmer JW. Higher transport and metabolism of glucose in astrocytes compared with neurons: a multiphoton study of hippocampal and cerebellar tissue slices. Cereb Cortex 2013 (in press)

[138] Bishop GM, Dang TN, Dringen R, Robinson SR. Accumulation of non-transferrinbound iron by neurons, astrocytes, and microglia. Neurotox Res 2011;19(3) 443-51.

[139] Dineley KT, Kayed R, Neugebauer V, Fu Y, Zhang W, Reese LC, Taglialatela G. Amyloid-beta oligomers impair fear conditioned memory in a calcineurin-dependent fashion in mice. Neurosci Res 2010;88(13) 2923-32.

[140] Simard A, Soulet D, Gowing G, Julien J, Rivest S. Bone marrow-derived microglia play a critical role in restricting senile plaques formation in Alzheimer disease. Neuron 2006;49 489-502.

[141] Block ML, Zecca L, Hong JS. Microglia-mediated neurotoxicity: uncovering the molecular mechanisms. Nat Rev Neurosci 2007; 8(1) 57-69.

[142] Maezawa I, Zimin P, Wulf H, Jin L. Amyloid-beta protein oligomer at low nanomolar concenrations activates microglia and induces microglial neurotoxicity. J Biol Chem 2011;286 3693-3706.

[143] Kauppinen TM, Higashi Y, Suh SW, Escartin C, Nagasawa K, Swanson RA. Zinc triggers microglial activation. J Neurosci 2008;28(22) 5827-35.

[144] Knoch ME, Hartnett KA, Hara H, Kandler K, Aizenman E. Microglia induce neurotoxicity via intraneuronal $\mathrm{Zn}(2+)$ release and a $\mathrm{K}(+)$ current surge. Glia 2008;56(1) 89-96.

[145] Vezzani A, French J, Bartfai T, Baram TZ. The role of inflammation in epilepsy. Nat Rev Neurol 2011;7 31-40.

[146] Aronica E, Gorter JA. Gene expression profile in temporal lobe epilepsy. Neuroscientist 2007;13 100-108. 
[147] Ravizza SM, Lucas S, Balosso L, Bernardino G, Ku F, Noé J, Malva JC, Randle S, Allan A. Inactivation of caspase-1 in rodent brain: a novel anticonvulsive strategy. Epilepsia 2006;47 1160-1168.

[148] Aronica K, Boer EA, van Vliet S, Redeker JC, Baayen WG, Spliet PC, van Rijen D, Troost FH, da Silva WJ, Wadman JA, Gorter JA. Complement activation in experimental and human temporal lobe epilepsy. Neurobiol Dis 2007;26 497-511.

[149] Iyer AM, Zurolo E, Boer K, Baayen JC, Giangaspero, F, Arcella A, Di Gennaro GC, Esposito V, Spliet WGM, van Rijen PC, Troost D, Gorter JA, Aronica E. Tissue plasminogen activator and urokinase plasminogen activator in human epileptogenic pathologies. Neuroscience 2010;19 929-945.

[150] Ballabh P, Braun A, Nedergaard M. The blood-brain barrier: an overview: structure, regulation, and clinical implications. Neurobiol Dis 2004;16 1-13.

[151] Lucas SM, Rothwell NJ, Gibson RM. The role of inflammation in CNS injury and disease. Br J Pharmacol 2006;147(Suppl. 1) 232-240.

[152] Maroso M, Balosso S, Ravizza T, Liu J, Aronica E, Iyer AM, Rossetti C, Molteni M, Casalgrandi M, Manfredi AA, Bianchi ME, A. Toll-like receptor 4 and high-mobility group box-1 are involved in ictogenesis and can be targeted to reduce seizures. Nat Med 2010;16(4) 413-419.

[153] Sheedy FJ, O'Neill LA. Adding fuel to fire: microRNAs as a new class of mediators of inflammation. Ann Rheum Dis 2008;67(Suppl. 3) 50-55.

[154] Colton CA, Gilbert DL. Production of superoxide anions by a CNS macrophage, the microglia. FEBS Lett 1987;223(2) 284-8.

[155] Park JK, Williams BP, Alberta JA, Stiles CD. Bipotent cortical progenitor cells process conflicting cues for neurons and glia in a hierarchical manner. J Neurosci 1999;19(23) 10383-9.

[156] Stoll G, Müller HW. Nerve injury, axonal degeneration and neural regeneration: basic insights. Brain Pathol 1999;9(2) 313-25.

[157] Feinstein DL, Galea E, Reis DJ. Suppression of glial iNOS expression by tyrosine kinase inhibitors. Ann N Y Acad Sci 1994;17(738) 325-8.

[158] Suwalsky M, Fierro P, Villena F, Aguilar LF, Sotomayor CP, Jemiola-Rzeminska M, Strzalka K, Gul-Hinc S, Ronowska A, Szutowicz A. Human erythrocytes and neuroblastoma cells are in vitro affected by sodium orthovanadate. Biochim Biophys Acta 2012;1818(9) 2260-70.

[159] Suwalsky M, Fierro P, Villena F, Gallardo MJ, Jemiola-Rzeminska M, Strzalka K, GulHinc S, Ronowska A, Zysk M, Szutowicz A. Effects of sodium metavanadate on in vitro neuroblastoma and red blood cells. Arch Biochem Biophys 2013;535(2) 248-56. 